\title{
Grammaticality judgment in French-speaking children with specific language impairment
}

\author{
CHRISTELLE MAILLART \& MARIE-ANNE SCHELSTRAETE
}

Université catholique de Louvain, Louvain-La-Neuve, Belgium

\begin{abstract}
Grammaticality judgement abilities were examined among French-speaking children with SLI. Rice, Wexler, and Redmond (1999) showed that children's grammatical judgements paralleled their production: they rejected morphosyntactic errors they were unlikely to commit (e.g., agreement errors), whereas they accepted morphosyntactic errors that they were likely to produce (e.g., violation of tense marking). According to the authors, their findings supported the extended optional infinitive (EOI) account of a morphosyntactic limitation in SLI children based on underlying grammatical representations. They did not support accounts of input processing deficits or production constraints. However, important methodological limitations have challenged their results. In our study, SLI children and their control counterparts were asked to detect different grammatical violations: (1) agreement errors; (2) violations of tense marking; or (3) a control measure: order violations. Contrary to the control children, SLI children appeared to be sensitive to the kind of modification to be detected. They detected significantly fewer verbal morphology-related violations (1 and 2 ) than order violations (3). These findings, which weaken Rice et al.'s results, are more compatible with other interpretations (e.g., phonological or cognitive) of grammatical disorders in SLI than with an EOI account.
\end{abstract}

Keywords: Specific language impairment, grammaticality judgment, agreement errors, EOI, morphological disorder, comprehension abilities

\section{Introduction}

Children with SLI are generally defined as presenting a significant limitation in language abilities that cannot be explained by any apparent factor such as hearing impairment, low verbal intelligence, neurological damage or psychological trouble (Stark, \& Tallal, 1981; Bishop, 1992). They have also been shown to present a large heterogeneity of verbal symptoms including major difficulties in grammatical morphology (for an overview, see Leonard, 1998). There are different competing accounts of the nature of these grammatical limitations. For some authors, the underlying grammatical representations were affected in children with SLI. For instance, Rice, Wexler, and Cleave (1995) proposed that these children's problem was caused by a lack in tense marking (Extended Optional Infinitive account, hereafter, EOI), while Clashen et al. (1997) suggested that a lack in verb agreement affected the production performance in children with SLI. For other authors, to the

Correspondence: Christelle Maillart, Unité Cognition \& Développement, Faculté de Psychologie et des Sciences de l'Education, 10 Place Cardinal Mercier, 1348 Louvain-la-Neuve, Belgium. E-mail: christelle.maillart@psp.ucl.ac.be 
contrary, the grammar of these children was intact and the limitations observed were due to other factors: production constraints (Bishop, 1994) or impaired input processing mechanisms (Tallal et al., 1996).

In this context, comprehension tasks proved useful as they made it possible to make different predictions depending on the theoretical framework. If the limited production performance was attributable to underlying grammatical representations, it should be evident in children's processing of the morphological forms as well as in their production. By contrast, the production constraint account predicted preserved comprehension or better performances in comprehension tasks. In order to evaluate this prediction for the EOI theory, Rice, Wexler, and Redmond (1999) developed a grammatical judgment task. They expected that the children with SLI would accept the grammatical items, but would also accept ungrammatical items including violation in tense marking. Children's judgments of sentences would parallel their productions, meaning that they would accept as grammatical the kinds of sentences they were likely to produce. Sentences with or without grammatical violations were presented to 20 English-speaking children with SLI (mean age: 6;0 years) and 18 language control children (mean age: 4;1 years) matching on MLU. The child's task was to tell the examiner whether the language was 'good' or 'not so good'. In this experiment, the authors showed that children's grammatical judgments paralleled their production: SLI children rejected morphosyntactic errors they were unlikely to commit (e.g., agreement errors: I likes toast), whereas they accepted morphosyntactic errors that they were likely to produce (e.g., violation of tense marking: he eat toast). Consequently, the authors claimed that their findings supported the EOI account of a morphosyntactic limitation in SLI children based on underlying grammatical representations and that they did not support accounts of input processing deficits or production constraints.

However, important methodological limitations have challenged such results. Firstly, most of the agreement errors proposed were constructed by adding erroneous morphemes (e.g., I drinks milk), while items with violations of tense marking were constructed in omitting morphemes (e.g., he drink milk). As it stands to reason that omissions would be more difficult to detect than additions, this variation in the material should favour the detection of violations of agreement. Secondly, the material presented a bias to reject sentences: two-thirds of the sentences included grammatical violations, while only one-third of the sentences did not include violations. Finally, the performances of children were not controlled for their difference from the random level. The purpose of this study was thus to replicate this experiment with French-speaking children with SLI in controlling the different bias presented above. For example, in the French language, morphological tense violations can be committed by substitution (e.g., 'ouvrir' for 'ouvre') in the same way as agreement errors (e.g., le garcon 'sont' assis in place of le garcon 'est' assis).

\section{Method}

\section{Participants}

Children with SLI. Sixteen monolingual French-speaking children with a clinical diagnosis of specific language impairment were included in the study. All these children had been diagnosed by a multidisciplinary team and had been undergoing regular language therapy for severe language disorders since they were 4 or 5 years old. In Belgium, the therapy addressed to children with SLI aims mainly to complete the linguistic input by the use of gesture. This therapy has a major communicative objective. No specific morphosyntactic treatment had been conducted. The children ranged from $7 ; 10$ to $11 ; 6$ years, with a mean 
age of 9;2 years. All these children presented a non-verbal IQ within normal range, no sensorineural hearing loss and no known physical or emotional cause for language impairment. Moreover, all the children in this study could be considered ER-SLI, following the classification of Evans (1996), i.e., they presented both expressive and receptive impairment (see Table I). They performed at -1.6 SD from the mean on the French version of the Test of Reception of Grammar (Ecosse, Lecocq, 1996) and they presented important expressive disorders.

Children with normal language abilities. Sixteen monolingual French-speaking children were selected to serve as language receptive level controls using matches based on the scores on the French version of the Test of Reception of Grammar (Ecosse, Lecocq, 1996). According to the teachers' report and background information supplied by the parents, these control children had no history of speech, language or hearing problems. They did not have any exceptional needs either. They ranged from $4 ; 0$ to $6 ; 9$ years, with a mean age of $5 ; 4$ years, and were in kindergarten or in grade 1 . The main characteristics of these 16 NLD children are displayed in Table I, where the significant differences between the two groups of children (NLD vs. SLI) are shown.

\section{Material}

As in Rice et al. (1999), the children were asked to detect different grammatical violations in sentences. A total of 72 sentences were proposed including 36 control sentences without grammatical violations and 36 experimental sentences with grammatical violations. These experimental sentences were further broken down into three states: (1) 12 sentences (EOI) with a grammatical violation compatible with EOI (e.g., Le garçon ouvrir* (inf - to) le livre: the boy open* the book); (2) 12 sentences (AGR) with a grammatical violation of the verb agreement (e.g., le garçon sont* assis/the boy are in a sitting position), both conditions constructed by the substitution of morphemes; and (3) 12 control (ORD) sentences with a grammatical violation of the word order (e.g., a la dame des roses lunettes*/has the woman glasses pink). According to Rice et al.'s predictions (1999), children with SLI would accept

Table I. Profiles of participant groups

\begin{tabular}{|c|c|c|c|c|c|c|c|}
\hline & \multicolumn{3}{|c|}{ NLD children $(n=16)$} & \multicolumn{3}{|c|}{ Children with SLI $(n=16)$} & \multirow{2}{*}{$\begin{array}{l}\text { Differences between } \\
\text { the groups ( } t \text { test) }\end{array}$} \\
\hline & Mean & S.D. & Range & Mean & S.D. & Range & \\
\hline $\begin{array}{l}\text { Chronological age } \\
\text { (in months) } \\
\text { Vocabulary }\end{array}$ & 64 & 12 & $43-83$ & 110,9 & 13 & $99-138$ & $p<.001$ \\
\hline $\begin{array}{l}\text { Lexical receptive } \\
\text { (PPVT, raw scores) } \\
\text { Morphosyntax }\end{array}$ & 53,87 & 15 & $32-80$ & 64,7 & 22 & $41-122$ & $p<.01$ \\
\hline $\begin{array}{l}\text { Sentence repetition } \\
\text { task (Isadyle, \% } \\
\text { corr.) }\end{array}$ & 86,5 & 10,1 & $63,3-100$ & 31,11 & 17,8 & $3,3-40$ & $p<.001$ \\
\hline $\begin{array}{l}\text { Sentence } \\
\text { comprehension } \\
\text { (Ecosse, \% corr.) }\end{array}$ & 76,76 & 8,1 & $60,8-91,3$ & 77,1 & 7,3 & $60,8-90,2$ & NS \\
\hline
\end{tabular}


EOI grammatical violations unlike the control children, but would reject other grammatical violations (AGR or ORD) like the control children.

\section{Procedure}

Each child was tested individually in a quiet room. All stimuli of the experimental task were recorded digitally and presented on a computer together with a picture of the action described. The child's task was to tell the examiner whether the sentence was 'good' or 'not so good'. Experimental items were preceded by introductory items in which feedback was given to establish the kinds of judgments of interest. No feedback was given after the experimental items.

\section{Results}

\section{Statistical analyses}

In order to compare with Rice et al.'s results (1999), the same statistical analyses were carried out. An adjusted measure of sensitivity $\left(A^{\prime}\right)$ - i.e., the proportion of correct responses achievable in a dual-alternative, forced-choice procedure - was calculated for each condition (see Figure 1). An analysis of variance was performed on the $A^{\prime}$ with groups (SLI vs. NLD) as a 'between subjects' variable and condition (AGR/agreement; EOI/tense; ORD/order) as a 'within subjects' variable. A group effect was found: $F(1,30)=7.87, p<0.01$ with an $A^{\prime}$ mean of $2.72(\mathrm{SD}=0.5)$ for the control group and an $A^{\prime}$ mean of $1.63(\mathrm{SD}=0.46)$ for the children with SLI. The effect of the condition was also significant, $F(2,60)=7.42, p<0.01$, but there was no group by condition interaction, $F(2,60)=1.54, p<0.21$. This latter result was probably due to a greater variability within the subjects of the control group: when the condition effect was examined by group, a significant effect of condition was observed in children with SLI, $F(2,30)=7.29, p<0.01$ while the effect was absent in control children, $F(2,30)=1.07, p<0.35$.

Contrary to Rice et al. (1999), it was verified whether children answered at random. To this end, a sensitivity index $\left(d^{\prime}\right)$ was computed for each participant. Despite the training items, half of the SLI participants (8/16) obtained a $d^{\prime}$ lower than 1 in the experimental task, which gave rise to the belief that these children answered at random, in accordance with the theory of Edwards, and Lahey (1996, p. 1273). Three of the 16 control children - the

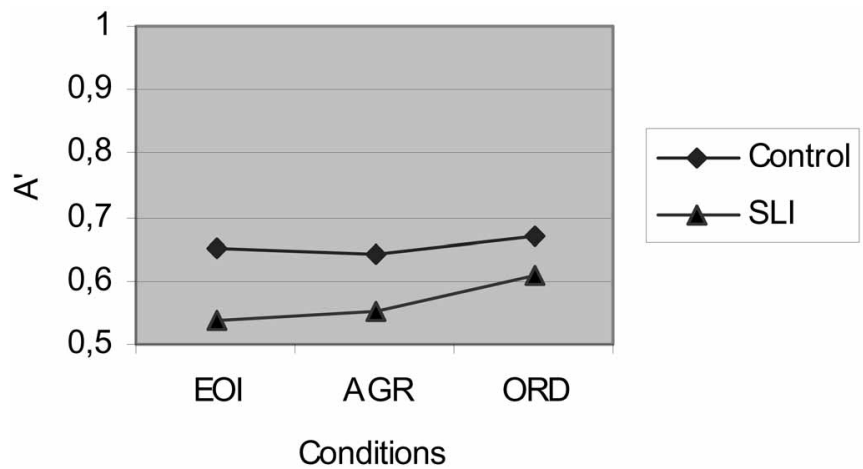

Figure 1. $A^{\prime}$ per condition, by group. EOI, extended optional infinitive; AGR, agreement; ORD, word order. 
youngest ones (4-year-olds) - also performed at random. ${ }^{1}$ These children and their controls were thus removed from the analyses reported below. Indeed, it was not reliable to observe the effect of a repeated variable within subjects performing at random.

New statistical analyses were conducted among children having performed differently from the random level. An analysis of variance was performed on the percentage of correct responses with group (SLI vs. NLD) as a 'between subjects' variable and the kind of responses given (acceptation of a grammatical sentence or rejection of an ungrammatical sentence) as a 'within subjects' variable. This analysis aimed at separating out the kind of responses given to attribute the respective contribution of judgments on grammatical or ungrammatical sentences to $d^{\prime}$ or $A^{\prime}$ performances. As observed previously, a group effect was found, $F(1,14)=12.99, p<0.01$ and a kind of response effect was observed, $F(1,14)=45.54, p<0.001$, as well as an interaction Group $\times$ Kind of response, $F(1,14)=12.52, p<0.01$. The interaction could be explained by a significant group effect in rejecting ungrammatical sentences, $F(1,15)=15.43, p<0.01)$ and the absence of this group effect in accepting correct sentences, $F(1,15)<1$. This pattern has been illustrated in Figure 2 .

As the main differences found between the groups concerned only ungrammatical sentences, an analysis of variance was carried out on the percentage of correct rejection using group (SLI vs. NLD) as the 'between subjects' variable and condition (AGR/ agreement; EOI/tense ; ORD/order) as the 'within subjects' variable. The group effect was confirmed, $F(1,14)=15.52, p<0.01$. The effect of condition was also significant, $F(2,28)=4.51, p<0.05$, as was the Group $\times$ Condition interaction, $F(2,28)=4.17$, $p<0.05$. The analysis of the interaction illustrated in Figure 3 suggests that the control children did not show a condition effect, $F<1$, while children with SLI showed a condition effect, $F(2,14)=8.11, p<0.01$. Contrary to the control children, the SLI children appeared to be sensitive to the kind of modification to be detected. They were significantly less efficient in detecting verbal morphology-related violations, without differences between agreement errors or violation of tense marking, than in detecting order violations. For the latter kind of error, SLI children were actually not different from the controls, $F(1,15)=1.7$, $p<0.27$.

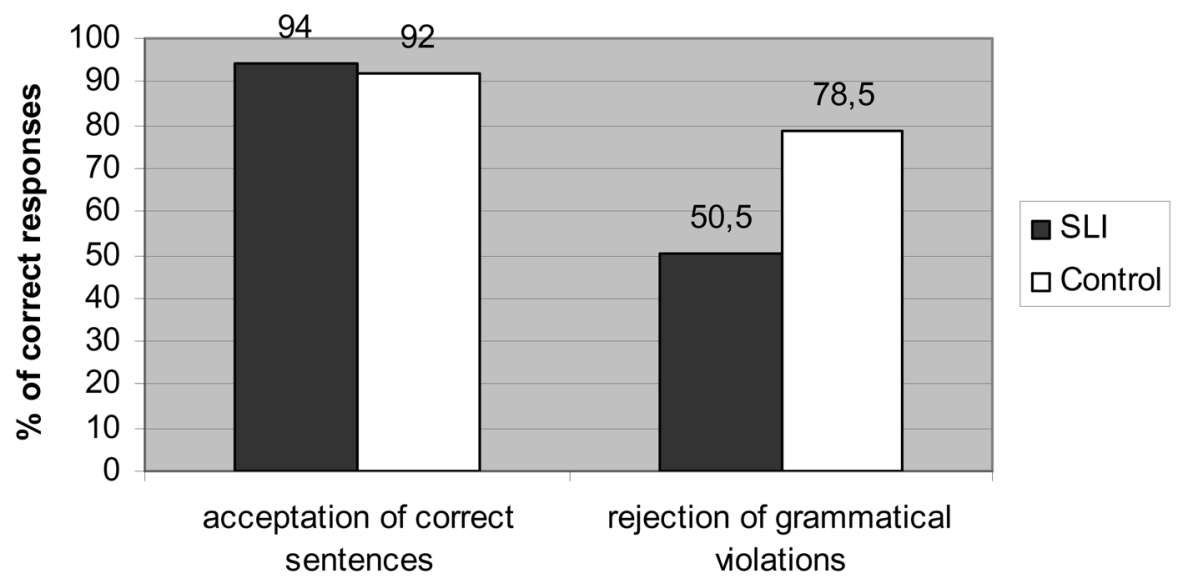

Figure 2. Percentage of correct responses by kind of response and group. 


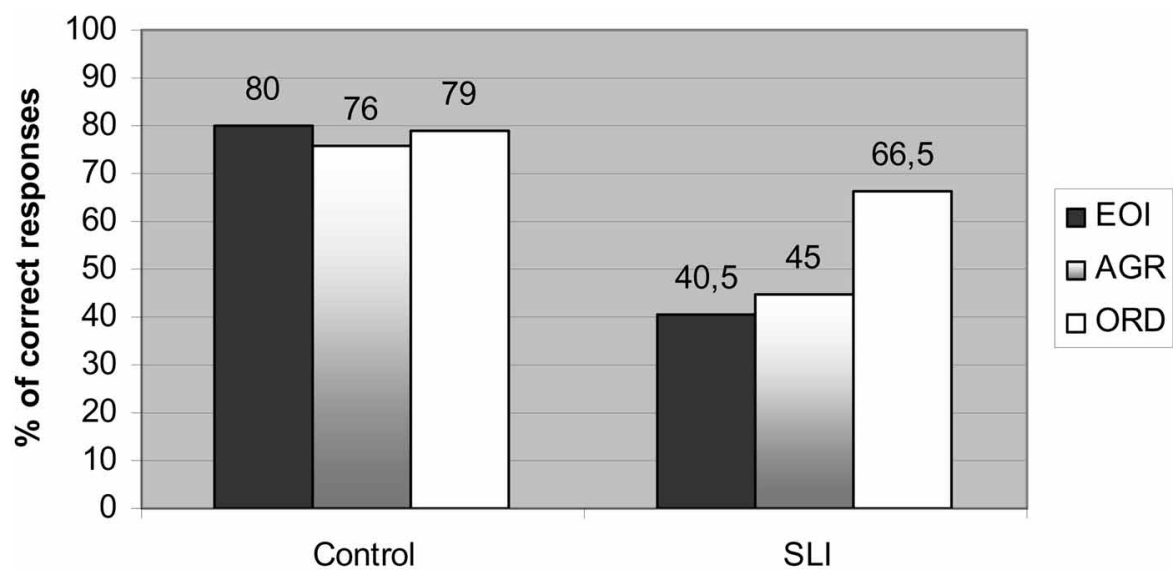

Figure 3. Percentage of correct rejection condition and group.

\section{Discussion and conclusion}

As in the study of Rice et al. (1999), a grammaticality judgment task was administered to children with SLI in order to understand the nature of their grammatical representations. Different grammatical violations (tense, agreement or word order) were proposed. Essentially, according to the EOI account, it could be expected that the children with SLI would accept grammatical violations compatible with their own grammatical representations, while they would reject other grammatical violations. The nature of the violations accepted or rejected should provide information about their grammatical representations.

Before further examining the grammatical violations accepted, the question of task complexity has to be discussed. In fact, grammaticality judgment tasks appeared to be particularly difficult for both children with SLI and younger control children. By contrast, the control children (aged 4;0) in Rice et al.'s study did not seem to present difficulties as suggested by a higher level of $A^{\prime}$. It was thus important to compare the performances of our control children with the data of the literature. A brief review of the studies dedicated to metalinguistic tasks such as grammaticality judgment suggested that this task was not reliable for such young children. Indeed, Ryan, and Ledger (1979) pointed out that this kind of judgment was not possible before 6 years of age; Tunmer, and Grieve (1984) showed that 4-5-year-old children could make semantic judgments, but that only 6 -7-year old children could make grammatical judgments. This latter suggestion was confirmed by Gombert (1990). So the performances of our participants were clearly compatible with the data of the literature, whereas the high scores of the control children of Rice et al. seem difficult to explain. These observations have an important implication: we need other ways to evaluate the comprehension level of young children than a complex metalinguistic task like the grammaticality judgment task. Consequently, the results obtained with this methodology in young children are questionable: Rice et al.'s study did not appear sufficient to prove the presence of an EOI stage in comprehension.

Moreover, when children performing at random level were excluded, the patterns of performances differed from those of Rice et al.'s study. The children with SLI presented specific difficulties in detecting grammatical violations dealing with morphological forms (agreement and tense), while they efficiently rejected order violations. In contrast, in Rice et al.'s study, only tense violations were accepted while agreement violations were rejected, 
which was the pattern predicted by the EOI account. However, as previously noted, a confusing variable could account for this pattern: agreement violations were built by substitution or addition while tense violations were built by omission of morphemes. In our study, this bias was neutralised (all the modifications were built by substitution), hence leading the difference between these conditions to disappear. In fact, neither the EOI account nor the agreement account can explain our results. Our results seem compatible with a more general morphological deficit. Nevertheless, different questions remain open: would be it a perceptive effect compatible with limited input processing mechanisms or could this pattern be attributed to a morphophonological effect? In order to answer these questions, further research is needed.

\section{Note}

[1] Many of these children performed at random level. In order to control this point, we administered our task to 15 other 4-year-old control children. The results were clear: only one of these children performed differently from the random level.

\section{References}

Bishop, D.V.M. (1992). The underlying nature of specific language impairment. Fournal of Child Psychology and Psychiatry, 33, 1-64.

Bishop, D.V.M. (1994). Is specific language impairment a valid diagnostic category? Genetic and psycholinguistic evidence. Philosophical Transactions of the Royal Society, B, 346, 105-111.

Clahsen, H., Bartke, S., \& Göllner, S. (1997). Formal features in impaired grammars: A comparison of English and German SLI children. fournal of Neurolinguistics, 10, 151-171.

Edwards, J., \& Lahey, M. (1996). Auditory lexical decision of children with specific language impairment. Fournal of Speech and Hearing Research, 39, 1263-1273.

Evans, J. (1996). SLI subgroups: Interaction between discourse contraints and morpho-syntactic deficits. Fournal of Speech and Hearing Research, 39, 655-660.

Gombert, J.E. (1990). Le développement métalinguistique. Paris: PUF.

Lecocq, P. (1996). L'E.CO.S.SE. Une épreuve de compréhension sémantico-syntaxique. Villeneuve d'Ascq: Presses Universitaires du Septentrion.

Leonard, L.B. (1998). Children with specific language impairment Cambridge: MIT Press.

Rice, M.L., Wexler, K., \& Cleave, P.L. (1995). Specific language impairment as a period of extended optional infinitive. Fournal of Speech, Language and Hearing Research, 38, 850-863.

Rice, M.L., Wexler, K., \& Redmond, S.M. (1999). Grammatically judments of an extended optional infinitve grammar: Evidence from English-speaking children with specific language impairment. Fournal of Speech, Language and Hearing Research, 42, 943-961.

Ryan, E.B., \& Ledger, G.W. (1979). Grammaticality judgments, sentence repetitions, and sentence corrections of children learning to read. International fournal of Psycholinguistics, 6, $23-40$.

Stark, R.E., \& Tallal, P. (1981). Selection of children with specific language deficits. Fournal of Speech and Hearing Disorders, 46, 114-122.

Tallal, P., Miller, S.L., Bedi, G., Byma, G., Whang, X., Nagarajan, S.S., Schreiner, C., Jenkins, W.M., \& Merzenich, M.M. (1996). Language comprehension in language-learning impaired children improved with acoustically modified speech. Science, 271, $81-84$.

Tunmer, W.E., \& Grieve, R. (1984). Syntactic awareness in children. In: W.E. Tunmer, C. Pratt, \& M.L. Herriman (Eds), Metalinguistic awareness in children. Berlin: Springer Verlag. 